Article

\title{
Green Coalescent Synthesis Based on the Design for Environment (DfE) Principles: Brazilian Experience
}

\author{
Isadora Luiza Climaco Cunha, Fábio Rosa and Luiz Kulay *D

\begin{abstract}
Chemical Engineering Department, Polytechnic School, University of São Paulo, Avenida Professor Lineu Prestes, 580, Block 18-Conjunto das Químicas, São Paulo 05508-000, SP, Brazil; isadoracunha@usp.br (I.L.C.C.); fabiorosa@usp.br (F.R.)

* Correspondence: luiz.kulay@usp.br; Tel.: +55-11-3091-2233
\end{abstract}

Citation: Cunha, I.L.C.; Rosa, F.; Kulay, L. Green Coalescent Synthesis Based on the Design for Environment (DfE) Principles: Brazilian Experience. Sustainability 2021, 13, 12802. https:// doi.org/10.3390/su132212802

Academic Editors: Prateek Saxena,

Giuliano Bissacco and

Konstantinos Salonitis

Received: 3 October 2021

Accepted: 15 November 2021

Published: 19 November 2021

Publisher's Note: MDPI stays neutral with regard to jurisdictional claims in published maps and institutional affiliations.

Copyright: (c) 2021 by the authors. Licensee MDPI, Basel, Switzerland. This article is an open access article distributed under the terms and conditions of the Creative Commons Attribution (CC BY) license (https:// creativecommons.org/licenses/by/ $4.0 /)$.

\begin{abstract}
Coalescents are compounds with a high potential for generating tropospheric ozone, which causes adverse effects on humans and their surroundings. This study designed a coalescent for decorative paints that reached technical levels equivalent to those obtained by StC, a product on the market, but with better environmental and economic performance. The strategy adopted in creating the green coalescent $(\mathrm{GrC})$ improved film formation and reduced the product's atmospheric emission rate. Regarding the environmental performance, $\mathrm{GrC}$ outperformed StC in terms of water consumption, global warming potential, and human toxicity by $30 \%, 35 \%$, and $91 \%$, but had a high smog formation potential even with a reduced loss to the air. The redesign of the molecule gave rise to $\mathrm{AGrC}$, which achieved a more homogeneous environmental performance. The results of an economic analysis indicated that the procedures adopted to reduce environmental impacts could also make the coalescent more competitive if the lowest market prices were practiced. On the other hand, if the products are sold at high prices, the paint industry tends to privilege the economic dimension and disregard environmental performance for decision purposes. This research succeeded in reconciling technical functions and aspects related to sustainability to design more competitive products in the Brazilian market.
\end{abstract}

Keywords: green coalescent; design for environment; life cycle assessment; ecoefficiency analysis; green chemistry

\section{Introduction}

Coalescents are solvent-class products routinely incorporated in water-based paint formulations containing polymeric emulsions as binders to improve their application [1]. In addition to providing polymeric phase plasticity without structural changes, these agents also optimize the formation of films, resulting in continuous and homogeneous finishes under different conditions of temperature and humidity [2]. Its presence in the solution also makes the coating more 'ecological' compared to traditional recipes that use organic dispersants to fulfill the same functions [3].

In 2020, the global coalescent market collected around 690 M USD in revenues from the production of $383 \mathrm{kt}$ of products, with $72 \%$ of this total destined for architectural paint production. However, these intermediates are also used in the preparation of automotive paints, wood coatings, traffic markers and other covering agents. During the same period, the Brazilian chemical sector gathered 14.0 M USD from the manufacturing of $7.5 \mathrm{kt}$ of coalescents, placing the country among the fifteen largest producers of these assets on the global scale. Projections indicate that the Brazilian market will experience a 5.2\% volume expansion by 2025 , which would increase revenues by $4.0 \%$ [4].

Coalescents must be stable in the presence of water, compatible with other paint formulation components, and incapable of destabilizing polymer particles dispersed in the medium to achieve the expected efficiency [5]. They also require high volatilization power, even though their boiling points must be increased $\left(>240^{\circ} \mathrm{C}\right)$ to support the film 
formation process [6]. As it fulfills all these requirements and properties, 2,2,4-trimethyl1,3-pentanediol monoisobutyrate is considered to be a reference coalescent by the paint and coating industry [7].

Regarding the scientific literature, coalescent concentration, hydrophobicity, and volatility effects on latex properties and film formation were investigated in [8]. In addition, coalescent influence on technical paint performance was also evaluated regarding glass transition temperature [9] and accelerated weathering [10].

European Union Directive 2004/42/EC classifies coalescents as volatile organic compounds (VOC) and tropospheric ozone $\left(\mathrm{O}_{3}\right)$ precursors capable of causing adverse effects on humans and animals, such as eye irritation, allergic reactions, and respiratory issues [11,12]. Intensification of regulations forced manufacturers to conceive products with low VOC content [13]. In this field, studies were carried out by the authors of [2], who developed water-based reactive molecules analogous to hydroxyethyl sulfone, and of [14], who explored the replacement of coalescents with hybrid latex particles.

In this context, techniques providing coherent analyses concerning the environmental performance of coalescent production and use become paramount in efforts to design new products (or readjust those available on the market) to make them less aggressive. Life cycle assessment (LCA) comprises an alternative capable of meeting these expectations as it prepares conceptually robust diagnoses supported by the ISO 14040 and 14044 standards $[15,16]$. Moreover, LCA quantifies the environmental impacts generated throughout a product's life cycle, i.e., from the extraction of material and energy resources to their final disposal in the biosphere in the form of goods that can no longer fulfill their original functions. However, studies in which LCA was related to paints and their components only verified the effects of alternative formulation materials [17-22] or measured the degree of return from innovative construction concepts [23-26]. In these situations, the coating figured only in supporting roles.

Some reports of successful experience applying LCA to assess the environmental performance of installed industrial processes or those displaying implementation potential in Brazil have been published more recently [27-35]. However, in all these cases, the technique was employed in the scope restricted to the production cycle (from cradle-to-gate) to identify environmental arrangement bottlenecks and propose improvement actions based on engineering conduct and management practices. Furthermore, these records do not refer to LCA applications in paint production activities and their components. Therefore, this study aimed to contribute to the theme by designing a coalescent for decorative paints that would achieve technical performance equivalent to that obtained by the counterpart available on the market, causing lower environmental impacts and being more competitive in economic terms. For this to occur, the environmental performance of a coalescent obtained according to the design for environment principles (green coalescent: $\mathrm{GrC}$ ) was evaluated by the LCA in the cradle-to-grave scope and compared to that of 2,2,4-trimethyl-1,3-pentanediol monoisobutyrate, named standard coalescent (StC). Likewise, the calculation of costs associated with each manufacture was carried out considering a comprehensive perspective. Finally, the study discusses the effects of integrating environmental and economic dimensions performing an ecoefficiency analysis (EEA).

Given its innovative character, the research became viable only after signing a technicalacademic collaboration agreement between a Brazilian multinational company that works in the surfactants and chemical specialties market and the Chemical Engineering Department of the University of São Paulo Polytechnic School (DEQ-EPUSP).

\section{Backgrounds}

The project that gave rise to GrC began in 2015 from an agreement signed between the company's research and development (R\&D) board and the Center for Environmental Research and Technology at the University of California, Riverside. The initiative's objective was to design a coalescent with high plasticizing capacity for acrylic and vinyl polymers, capable of reducing the minimum film-forming temperature (MFFT) and thus producing 
continuous, homogeneous, wet abrasion-resistant paint films with a lower tendency to dirt pick-up and leaching even under adverse weather conditions [36]. In addition, it would be equally important that the product present low odor levels and VOC emissions when being applied. The strategy adopted by the researchers was to elaborate a structure whose types of chemical bonds and radical arrangements would give rise to a stable molecule and with a boiling point higher than $250{ }^{\circ} \mathrm{C}$. As a result of these interventions, the team hoped to improve film formation and reduce the rate of coalescent emission into the atmosphere during the drying phase.

After three years of research, the project met expectations by synthesizing a robust molecule with stable physicochemical properties, mature technology, and high application yields. Reaching this level triggered the second phase of planning associated with investigating the coalescent's environmental performance. In this case, the team included R\&D professionals from the company and researchers from DEQ-EPUSP. In searching for conclusive results, the experts proposed that environmental $\mathrm{GrC}$ effects be compared to StC effects under identical conditions. For this purpose, the agents would be incorporated into water-based latex paints with the same qualitative and quantitative formulations except for the coalescent. The coatings would then be applied to the external surface so that the impacts associated with this activity could be evaluated alongside those from the GrC and StC production cycles. Apart from the environmental assessment, the team carried out an economic GrC analysis and opted to compare its performance to that of StC.

\section{Materials and Methods}

In operational terms, this phase of the project consisted of the following activities: (i) a literature review to identify technological aspects, operating conditions, and consumption and emissions of mass and energy associated with $\mathrm{StC}$ and $\mathrm{GrC}$ processing stages and the formulation of the building paint and its application; (ii) the application of the LCA technique to diagnose environmental impacts related to each system; (iii) an economic analysis to verify the magnitude of the participation of each coalescent in the total costs of their respective paints; and, finally, (iv) an investigation of synergies and divergences caused by the integration between the environmental and economic performance of each system through an ecoefficiency analysis.

\subsection{Modeling Standard Coalescent and Green Coalescent Production Processes and Developing Paint Preparation}

\subsubsection{Standard Coalescent Synthesis (StC)}

$\mathrm{StC}$ has been the market leader in coalescents applied in architectural paints for a few decades. However, legal industrial secrecy and intellectual protection instruments prevent technical and operational aspects related to its synthesis from being revealed with a high level of detail (for example, those exempted from technologically established processes) despite this recognition. Because of this restriction, the artifice found by the project team to model the process was to create computer models based on literature data, consistently describing the arrangement in terms of technology, consumption, and emissions.

After performing a rigorous search on different academic bases, the study carried out by the authors of [37] was considered a reference due to its compatibility with the research proposal. However, although quite detailed, the publication was imprecise (or silent) in some respects. These gaps were filled by recommendations made by the team's experts.

The data obtained from these procedures were entered into the Aspen Plus ${ }^{\circledR} \mathrm{V} 9.0$ software-Aspentech [38]. Given the conditions under which the simulations would occur, the team adopted a conservative approach based on state property methods equations to calculate the equilibrium distribution ratio, which was then used to determine equilibrium conditions.

The Peng-Robinson method was selected among other available options in this followup to perform these estimates. The choice of such an approach was based on that the PengRobinson (PR) equation of state is widely used to calculate the thermodynamic properties 
of a wide range of pure fluids and mixtures, in addition to performing multicomponent liquid-vapor phase equilibrium calculations [39]. If, on the one hand, the PR equation is not as accurate as some of its counterparts, on the other hand, this limitation is compensated by the ease with which it makes estimates and the low requirement for parameters for determining the properties of pure fluids (i.e., critical temperature and pressure, specific heat, fugacity, and the acentric factor) and nonideal mixtures (partial fugacity coefficient and binary interaction) [40]. This condition was fundamental to describe with the precision and accuracy the modeling required the steps of the StC processing, whose dataset was not fully available in the literature.

The StC synthesis is carried out in three steps. The first comprises isobutyraldehyde $\left(\mathrm{C}_{4} \mathrm{H}_{8} \mathrm{O}\right)$ trimerization catalyzed by sodium hydroxide $(\mathrm{NaOH})$. Although the reaction exhibits high selectivity in terms of StC formation, other byproducts, such as isobutyric acid $\left(\mathrm{C}_{4} \mathrm{H}_{8} \mathrm{O}_{2}\right)$, 2,2,4-trimethyl-1,3-pentanediol, and a mixture of StC and 2,2,4-trimethyl1,3-pentanediol diisobutyrate (TXIB) are also formed in the reaction medium. Operated at $101 \mathrm{kPa}$ and $50-70^{\circ} \mathrm{C}$, the reactor is lined with a cooling jacket to maintain this temperature plateau due to the exothermic nature of the transformation. The transformation is stopped by the addition of hydrochloric acid $(\mathrm{HCl})$ which upon contact with alkali produces sodium chloride $(\mathrm{NaCl})$. To simulate this step of the process, it was assumed that the reactions would take place in a stoichiometric reactor (REC1) maintained at $\mathrm{T}=60^{\circ} \mathrm{C}$ and $\mathrm{P}=101 \mathrm{kPa}$ (Figure 1). Equations (1) and (2) describe the StC synthesis, while Equation (3) depicts the interruption of the process due to $\mathrm{HCl}$ addition.

$$
\begin{gathered}
\mathrm{NaOH}_{(\mathrm{s})} \rightarrow \mathrm{NaOH}_{(\text {sol })} \\
3 \mathrm{C}_{4} \mathrm{H}_{8} \mathrm{O} \rightarrow \mathrm{C}_{12} \mathrm{H}_{24} \mathrm{O}_{3}(\mathrm{CSt}) \\
\mathrm{NaOH}+\mathrm{HCl} \rightarrow \mathrm{NaCl}+\mathrm{H}_{2} \mathrm{O}
\end{gathered}
$$

According to [37], the conversion rate of $\mathrm{C}_{4} \mathrm{H}_{8} \mathrm{O}$ to $\mathrm{StC}$ is $86.2 \%$. This value is reached by employing $6.25 \mathrm{~g}$ of a $40 \%{ }_{\mathrm{w} / \mathrm{w}} \mathrm{NaOH}$ solution $(62.5 \mathrm{mmol})$ and $4 \mathrm{~h}$ reaction time. To ensure consistency of the material equilibrium, all $\mathrm{NaOH}$ was considered to be consumed from excess $(74.0 \mathrm{mmol}) \mathrm{HCl}$ in the system. In addition to $\mathrm{StC}$ and its coproducts, the stream that leaves the reactor is composed of excess $\mathrm{C}_{4} \mathrm{H}_{8} \mathrm{O}, \mathrm{NaCl}$, and $\mathrm{HCl}$. The inorganic acid, its corresponding salt, and part of isobutyraldehyde $\left(10.9 \%_{\mathrm{w} / \mathrm{w}}\right)$ are separated from other chemical species by filtration. In the simulation, this unit operation was represented by a SPLITTER.

The next step comprises StC purification, whose minimum degree required for commercialization is $98.5 \% \mathrm{w} / \mathrm{w}$. The process, which takes place from successive distillations, begins when the mixture of compounds from filtration feeds the first tower COL1 that operates at atmospheric pressure. Volatile fractions, $\mathrm{C}_{4} \mathrm{H}_{8} \mathrm{O}_{2}$, and excess $\mathrm{C}_{4} \mathrm{H}_{8} \mathrm{O}$ come out in the top stream of the equipment. Heavy molecules, on the other hand, compose the undercurrent of COL1, which follows COL2. In this tower, which operates under vacuum (1.30 kPa), 2,2,4-trimethyl-1,3-pentanediol is separated from the StC/TXIB system.

Type DSTWU distillation towers, whose specification is based on the concept of light and heavy keys, were used to simulate COL1 and COL2 behaviors. After exploratory tests, the experts observed that the ratios for condenser $\left(r_{c}\right)$ and reboiler $\left(r_{r b}\right)$ refluxes, essential parameters to specify the recovered components in each stream, should be $r_{c}=r_{r b}=1.50$ in both cases. With this, the concentrations obtained at the output of each piece of equipment correspond to their estimated values, and the number of theoretical trays (NTT) was calculated as $\mathrm{NTT}_{\mathrm{COL} 1}=32$ and $N T T_{\mathrm{COL} 2}=40$. 


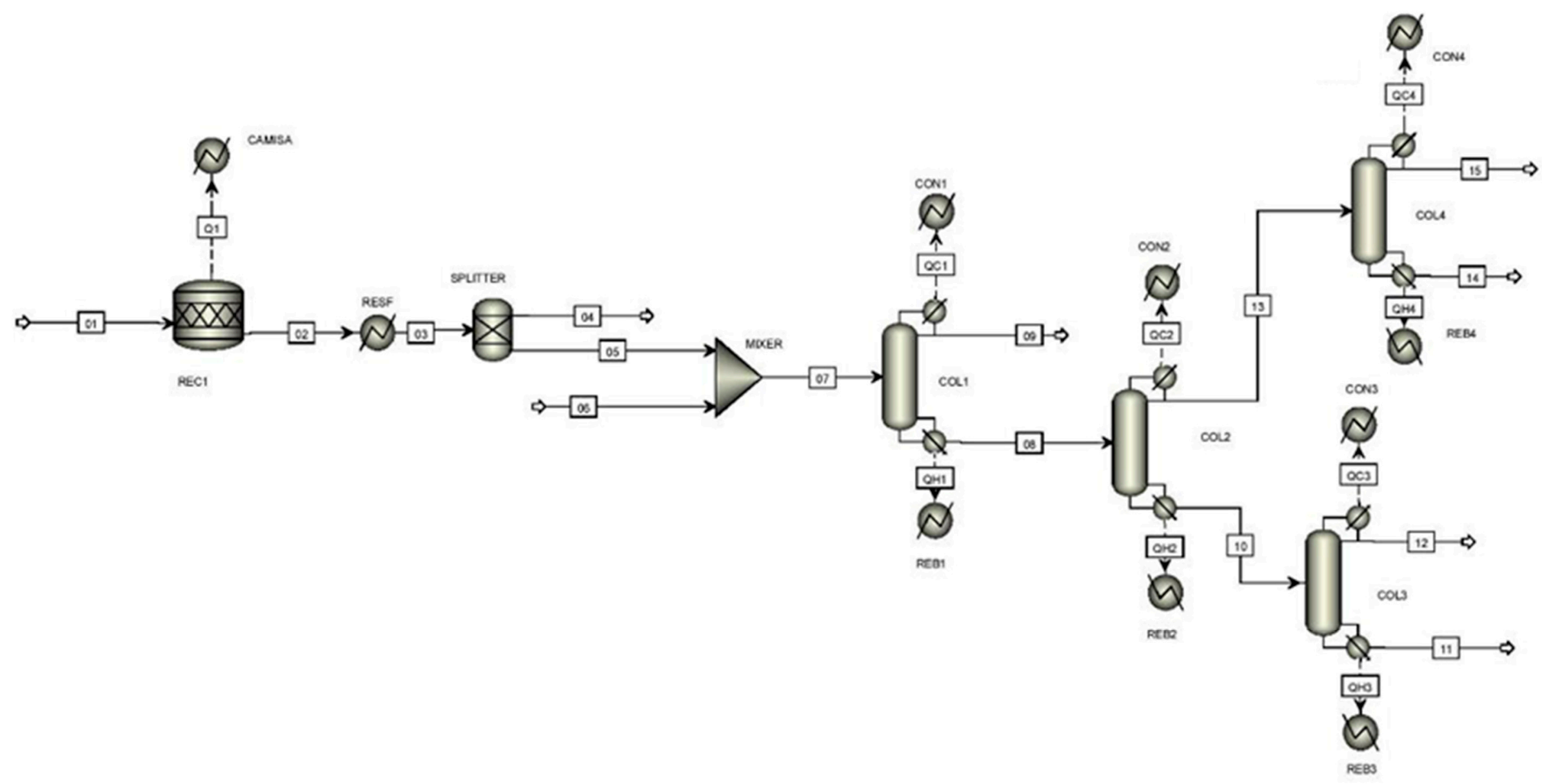

Figure 1. General flowchart of the StC processing generated from the literature data and with the aid of the Aspen Plus ${ }^{\circledR}$ software. 
StC purity was achieved by coupling two other distillation towers (COL3 and COL4) to the system, which are fed, respectively, by the top and bottom COL2 currents. Although there are no records in the literature indicating that the StC synthesis occurs in exactly this way, such chaining is usual and technologically viable [41,42] for the separation of high-molecular-weight compounds.

In procedural terms, it was admitted that COL3 operates under vacuum $(1.33 \mathrm{kPa})$, while StC and TXIB fractionation in COL4 would take place under atmospheric pressure. Regarding the simulation, the two devices were represented by columns of the Distl type. If, on the one hand, these modules are more demanding than the DSTWU regarding the specification of sizing parameters, on the other hand, they are also more versatile and robust than their counterparts. Model refinement indicated that the towers would exhibit numbers of theoretical trays, respectively, of $N T T_{C O L 3}=14$ and $N T T_{C O L 4}=26$. In addition, values of $r_{c}=r_{r b}=2.00$ were estimated for both cases with reference to the commercial purity grade of $\mathrm{StC}$.

The StC production simulation projected the overall thermal load associated with the unit's heat exchangers. Tap water was used as the cold utility and the temperatures of the condenser output currents were homogenized at $T_{c}=70^{\circ} \mathrm{C}$. On the other hand, dry saturated steam $\left(\mathrm{P}=40\right.$ bar; $\mathrm{T}=250{ }^{\circ} \mathrm{C}$ ) was used as the hot utility. In this case, it was assumed that only the fluid's latent heat would be exchanged during the heating processes. Table 1 presents the final values of the cold and hot utility flows employed in the process.

Table 1. Consumption of cold and hot utilities for the StC processing.

\begin{tabular}{|c|c|c|c|}
\hline \multicolumn{2}{|c|}{ Equipment } & \multirow{2}{*}{$\frac{\text { Mass Flow }\left(\mathbf{k g ~ h} \mathbf{~ h}^{-\mathbf{1}}\right)}{170}$} & \multirow{2}{*}{$\begin{array}{c}\text { Utility } \\
\text { cold }\end{array}$} \\
\hline Reactor & $R E C 1$ & & \\
\hline \multirow{4}{*}{ Condenser } & CON1 & 148 & cold \\
\hline & CON2 & 285 & cold \\
\hline & CON3 & 25.0 & cold \\
\hline & CON4 & 92.5 & cold \\
\hline \multirow{4}{*}{ Reboiler } & REB1 & 51.0 & hot \\
\hline & $R E B 2$ & 27.5 & hot \\
\hline & $R E B 3$ & 4.00 & hot \\
\hline & $R E B 4$ & 16.0 & hot \\
\hline
\end{tabular}

\subsubsection{Green Coalescent (GrC) Synthesis}

The green coalescent is still in the market consolidation phase and, because of that, its processing must be detailed in a general way. The synthesis of $\mathrm{GrC}$ is carried out according to two-stage alkoxylation, a symmetrical cyclic ether of low complexity (the most frequent option, in this case, is ethylene oxide), and a cyclic hydrocarbon linked to a hydroxyl group (generally, phenol). The transformation is aided by an inorganic catalyst and a support agent (short-chain organic acid) and occurs in a batch reactor. The vessel is dimensioned to withstand temperatures up to $200{ }^{\circ} \mathrm{C}$ and pressures above 10 bar. In addition, as this is an exothermic process, the facility must have an indirect contact cooling system to regulate the temperature of the reaction mass. Finally, reaction products are separated by filtration, but not before circulating through a deodorizing unit. This succession of operations makes $\mathrm{GrC}$ reach a final temperature below $70{ }^{\circ} \mathrm{C}$, and thus it is in conditions to be packed.

The process does not generate material or energy losses of any kind. However, it consumes thermal energy in the form of steam to drive transformation kinetics of the process and electricity to move agitators, pumps, and other peripheral equipment.

Table 2 shows the mean operating values for the GrC synthesis. As they define nominal conditions, these parameters were considered for the purpose of elaborating the technological model that describes the arrangement. 
Table 2. Nominal operating conditions for the GrC processing.

\begin{tabular}{ccc}
\hline Process Step & Equipment/Parameter & Specification/Average Value \\
\hline \multirow{3}{*}{ Reaction } & reaction vessel & Batch (transient state) \\
& cooling system & indirect \\
& cooling fluid & water \\
& $\mathrm{T}\left({ }^{\circ} \mathrm{C}\right)$ & $150-170$ \\
& $\mathrm{P}(\mathrm{bar})$ & $2.0-15$ \\
$\eta(\%)$ & $90+$ \\
\hline \multirow{2}{*}{ Deodorizing } & $\mathrm{T}\left({ }^{\circ} \mathrm{C}\right)$ & $100-120$ \\
& $\mathrm{P}(\mathrm{bar})$ & 1.0 \\
\hline \multirow{2}{*}{ Separation } & Filtration & basket filter \\
& $\mathrm{T}\left({ }^{\circ} \mathrm{C}\right)$ & $<70$ \\
& $\mathrm{P}(\mathrm{bar})$ & 1.0 \\
\hline
\end{tabular}

Legend: T: temperature; P: pressure; $\eta$ : theoretical yield.

\subsubsection{Building Paint Preparation}

The manufacturing routes of latex decorative wall paints formulated using the standard coalescent (WP-StC) and the green coalescent (WP-GrC) are identical and trivial. They consist of the simultaneous addition of raw materials and inputs to a stirred vessel that operates under ambient conditions. Mixing takes place for 15-20 min. The typical amounts of assets that make up WP-StC and WP-GrC are indicated in Table 3. The values were obtained from different paint suppliers, with low discrepancies between them.

Table 3. Average qualitative and quantitative composition of WP-StC and WP-GrC paints.

\begin{tabular}{cc}
\hline Input & Relative Contribution $\left(\mathbf{\%}_{\mathbf{w} / \mathbf{w}}\right)$ \\
\hline Tap water & 37.5 \\
Resin (latex) & 31.0 \\
Pigments and fillers & 25.0 \\
Coalescent & 1.20 \\
Auxiliary assets & 5.30 \\
\hline
\end{tabular}

\subsection{Life Cycle Modeling}

As mentioned in Section 2, the objects investigated herein were WP-StC and WP$\mathrm{GrC}$. The environmental performance diagnoses of these products were prepared from an attributional LCA following the conceptual guidelines described in [16] for the cradle-tograve scope. Given high durability of the investigated paints, a functional unit (FU) was established for the analysis as follows: 'Protect $50 \mathrm{~m}^{2}$ of smooth and external surface to a building against wear and tear caused by bad weather, for a period of 5 years.' The following technical specifications were obtained from building paint manufacturers: (i) each liter of latex-based paint covers $18 \mathrm{~m}^{2}$ of surface per coat; and (ii) an average of three coats of paint are required to provide a uniform finish to smooth exterior building surfaces.

The same survey also indicated that (a) latex-based paints have an average density $\rho=1.30 \mathrm{~g} / \mathrm{cm}^{3}$ regardless of the coalescent employed in the formulation; and, (b) under normal exposure conditions, the average time between two paint applications for surface maintenance is 5 years. Finally, the performance tests carried out at the research center of the green coalescent producer demonstrated that WP-StC and WP-GrC exhibit identical performance in terms of application. The association of this information resulted in a reference flow $(F R)$ of $10.8 \mathrm{~kg}$ of paint $(8.30 \mathrm{~L})$ for environmental performance comparison of both products.

The WP-StC and WP-GrC product systems are similar to each other, consisting of the raw material production stages for resin (or latex), coalescent, pigments, water (which acts as a diluent), fillers and other additives, as well as the paint formulation and its application, utility generation, such as electricity, heat, and water and effluent treatments that meet 
the respective processing chains. Additionally, the transport of inputs and intermediate materials and the finished product are also part of the arrangements. As they differ only in the coalescent production cycle, the production schemes were described in a single flowchart presented in Figure 2.

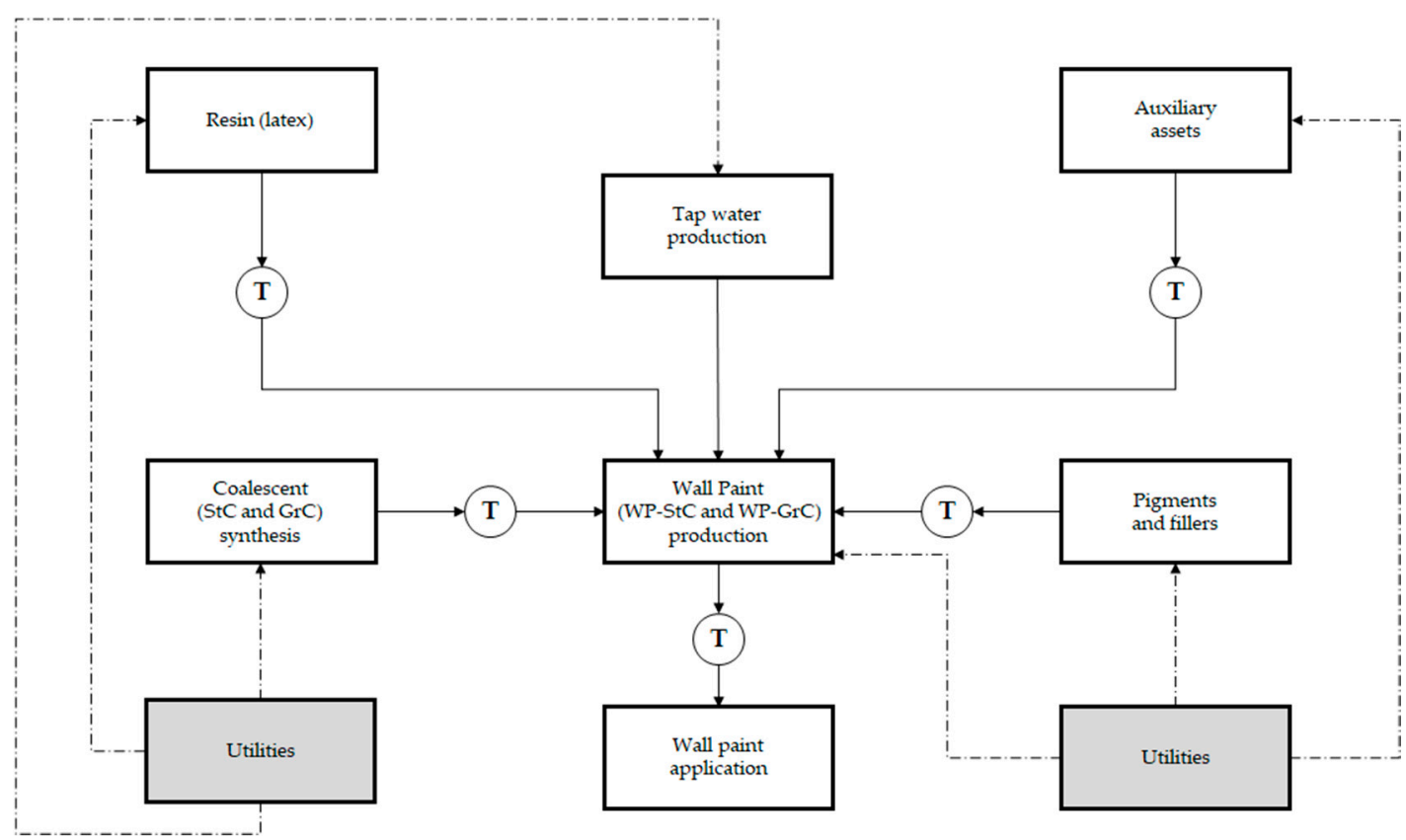

Figure 2. Schematic representation of the product system for the WP-StC and WP-GrC paints. Legend: $\longrightarrow:$ material flows; - : utility flows (material and energy); $\square$ : complete life cycle of raw materials and inputs; $\square$ : complete utility life cycle; (T): transport operation.

In line with the ISO guidelines [16], cut-off criteria based on cumulative mass and energy contributions were adopted for the intra-boundary modeling of product systems. In view of these specifications, material and energy streams whose contributions were less than $2.0 \%$ of the total accumulated input and output in the elementary processes and subsystems that made up each arrangement were no longer considered. On the other hand, the contributions of small currents that play specific roles in product systems, such as catalysts, active principles, purges, and small disposals, were also verified through environmental relevance criteria, being eventually reintroduced in the models despite their relative magnitudes. The multifunctionality situations identified in the product systems were provided by the Ecoinvent ${ }^{\circledR}$ database as follows: (i) diesel, fuel oil, and natural gas production via crude oil refining and raw natural gas, the intermediates used in the synthesis of isobutyraldehyde in the case of StC; (ii) ethylene oxide and phenol manufacturing (used in the $\mathrm{GrC}$ formulation); and (iii) the sanitary grounding systems adopted in this case as they are the most frequent alternative in Brazil for the disposal of this class of waste [43]. Multifunctionalities were treated by allocation procedure under the focus of the 'allocation at the point of substitution (APOS)' approach and based on physical criteria, again, following [16].

The confidentiality aspects presented previously justify the use of secondary data to describe consumption and emissions throughout the StC production chain. This contrasts with the specification of the environmental profile for the GrC manufacturing cycle, which is based on primary data provided by the coalescent manufacturer. Concerning temporal coverage, the primary data date from the 2018-2019 biennium when the $\mathrm{GrC}$ performance tests were validated. For secondary data, the temporal coverage was conditioned to the degree of timeliness of the life cycle inventories (LCIs) selected from the Ecoinvent ${ }^{\circledR}$ database to compose the models. With regard to geographic coverage, it was considered that the production of $\mathrm{GrC}$ and its constituents is carried out in Coatzacoalcos (Mexico), 
that the synthesis of StC and its components takes place in Longview (TX, USA), and that the formulations and applications of the WP-StC and WP-GrC paints occur in McCarran (NV, USA). The criteria guiding the selection of these locations are essentially marketbased. Finally, in relation to technological coverage, the StC and GrC processing and their corresponding paints followed the operational conducts described in Section 3.1.

The life cycle impact assessment (LCIA) was carried out employing different approaches. The environmental performance associated with WP-StC and WP-GrC in terms of the global warming potential (GWP) were verified by the IPCC 2013 100a method (including $\mathrm{CO}_{2}$ uptake) [44]. In very general terms, the method identifies the release of GWP precursors to the environment originating from the investigated product system and expresses their contributions in the form of $\mathrm{CO}_{2}$, the reference substance for that impact category. In this context, activities that result in $\mathrm{CO}_{2}$ uptake are accounted for as gains resulting from anthropic activity, thus receiving a negative sign. This procedure for quantifying global warming contributions is in accordance with the approaches practiced in [45-47]. The behavior of the same products regarding human toxicity (HT), water consumption (WC), and fossil depletion (FD) were investigated through the application of the ReCiPe method-Midpoint $(\mathrm{H})$ v 1.13 [48], which, given its current nature, continues to be frequently applied in LCA studies for diagnosis elaborations. Finally, TRACI $2.1 \mathrm{v} 1.05$ was adopted $[49,50]$ to measure adverse effects concerning smog formation (SF). This decision was based on the completeness and rigor with which TRACI 2.1 performs SF estimates, considered by the project team to be essential to accurately verify the effectiveness of $\mathrm{GrC}$ with regard to the assessed impact categories.

Life Cycle Inventory (LCI)

Table 4 presents the average data on the consumption of both materials (i.e., raw materials and inputs) and energy (heat) associated to the StC processing. These values were obtained through computer simulations considering the regular operating conditions of the process (Section 3.1.1).

Table 4. Estimated material and energy consumption for the production of $1.0 \mathrm{~kg}$ of StC.

\begin{tabular}{cc}
\hline & Inputs \\
\hline Material Inputs & Amount \\
\hline Isobutyraldehyde, $\mathrm{C}_{4} \mathrm{H}_{8} \mathrm{O}(\mathrm{kg})$ & 1.42 \\
Sodium hydroxide, $\mathrm{NaOH}(\mathrm{g})$ & 45.0 \\
Hydrochloric acid, $\mathrm{HCl}(\mathrm{g})$ & 49.0 \\
Cooling water $(\mathrm{kg})$ & 1.43 \\
\hline Energy Inputs & Amount \\
\hline Steam sat. $\left(40\right.$ bar, $\left.250^{\circ} \mathrm{C}\right)(\mathrm{kg})$ & 4.65 \\
\hline Material Outputs & Outputs \\
\hline Coalescent $\mathrm{StC}\left(98.5 \%{ }_{\mathrm{w}} / \mathrm{w}\right)(\mathrm{kg})$ & \\
\hline
\end{tabular}

The $\mathrm{NaOH}$ manufacturing process was modeled using the concept of the medium technology. According to [51], the most frequent processing routes for $\mathrm{NaOH}$ in the United States (US) are the diaphragm (64\%), membrane (25\%), and mercury cell $(11 \%)$ techniques. $\mathrm{HCl}$ production was portrayed by the direct reaction between hydrogen $\left(\mathrm{H}_{2}\right)$ and liquid chlorine $\left(\mathrm{Cl}_{2}\right)$, which corresponds to the most frequent technology applied in the region. The portion relating to cooling water corresponds to the make-up of this cold utility due to evaporation and purge in the unit's cooling tower. The steam consumption indicated in Table 4 refers to the sum of the individual REB1-REB4 consumptions.

For the purpose of modeling logistics and transport operations, it was assumed that $\mathrm{StC}$ and isobutyraldehyde are processed at the same plant, in Longview, while $\mathrm{NaOH}$ and $\mathrm{HCl}$ manufacturing occur in a unit located in Henderson (TX, USA), $59 \mathrm{~km}$ from Longview, 
with input transport taking place by road. On the other hand, StC transfer to the installation that manufactures the paint is performed by railway for $3159 \mathrm{~km}$.

Table 5 details the LCI for the synthesis of $1.0 \mathrm{~kg}$ of GrC. Given the confidentiality issues discussed in Section 3.1.2, the consumption associated with this processing was expressed in the form of variation ranges. The transport of the potassium hydroxide solution was modeled considering two suppliers. The first, responsible for $92 \%$ of the alkali supply, distributes the input by road from Tennessee (US) to Coatzacoalcos, traveling $3149 \mathrm{~km}$. The second supplier travels $627 \mathrm{~km}$ from Mexico City to Coatzacoalcos. The distribution logistics of glacial acetic acid are similar to that of $\mathrm{KOH}$ as it is produced in Texas and transported over $1836 \mathrm{~km}$ to Mexico by truck. The ethylene oxide supply also originates from two sources, both located in Coatzacoalcos, between 3.0 and $3.5 \mathrm{~km}$ from the $\mathrm{GrC}$ processing facility. Liquid $\mathrm{N}_{2}$ arrives at the same destination after traveling a little more than $15 \mathrm{~km}$, while phenol moves by road $(4334 \mathrm{~km})$ to the destination.

Table 5. Matter and energy consumption concerning the synthesis of $1.0 \mathrm{~kg}$ of $\mathrm{GrC}$.

\begin{tabular}{cc}
\hline & Inputs \\
\hline Material Inputs & Amount \\
\hline Potassium hydroxide, $\mathrm{KOH}\left(\mathrm{sol} .50 \%_{\mathrm{w}} / \mathrm{w}\right)(\mathrm{g})$ & $1.25-3.75$ \\
Glacial acetic acid, $\mathrm{C}_{2} \mathrm{H}_{4} \mathrm{O}_{2}(\mathrm{~g})$ & $1.00-4.00$ \\
Ethylene oxide, $\mathrm{C}_{2} \mathrm{H}_{4} \mathrm{O}(\mathrm{g})$ & $100-500$ \\
Nitrogen, $\mathrm{N}_{2}(\mathrm{~g})$ & $5.00-10.0$ \\
Phenol, $\mathrm{C}_{6} \mathrm{H}_{6} \mathrm{O}(\mathrm{g})$ & $450-750$ \\
Cooling water $(\mathrm{g})$ & $500-750$ \\
\hline Energy Inputs & Amount \\
\hline Steam $(\mathrm{kg})$ & $0.25-0.60$ \\
Electricity $(\mathrm{kWh})$ & $0.05-0.30$ \\
\hline Material Outputs & Outputs \\
\hline Coalescent GrC $\left(98.5 \%{ }_{\mathrm{w}} / \mathrm{w}\right)(\mathrm{kg})$ & 1.00 \\
\hline
\end{tabular}

Datasets describing the energy matrices for Mexico (MX grid) and the United States (US grid) were obtained from the Ecoinvent ${ }^{\circledR}$ database. The LCIs were adjusted to the temporal coverage defined for the study incorporating data and information published in [52].

The steam consumed by the $\mathrm{GrC}$ synthesis at the Coatzacoalcos plant is generated from diesel combustion. Under nominal operating conditions, each ton of fuel produces $15.0 \mathrm{t}$ of superheated steam $\left(\mathrm{P}=9.0 \mathrm{bar}, \mathrm{T}=179{ }^{\circ} \mathrm{C}\right)$. The environmental loads generated from this production were modeled using a modified version of the Ecoinvent ${ }^{\circledR}$ 'Light fuel oil, burned in boiler $10 \mathrm{~kW}$, non-modulating/CH $U^{\prime}$ dataset by including real data. Transportation of StC from Longview to McCarran, where paint production takes place, is carried out by truck and covers a distance of $3159 \mathrm{~km}$. In the case of $\mathrm{GrC}$, which departs from Coatzacoalcos, this transfer comprises $4496 \mathrm{~km}$ of highways.

Since this study seeks to verify the environmental and economic effects caused by the green coalescent on the use of an architectural paint, the project team decided to treat the other assets that make up the coating formulation as elementary flows. Thus, the environmental loads associated with obtaining those raw materials and inputs were no longer considered in the analysis. We also admitted that the coalescent atmospheric emission would be the only source of impact of the paint application stage. In this context, while the literature reports losses of $90 \%$ w/w StC for the conditions under which the diagnosis is performed [53], laboratory tests indicate that $52 \% \%_{w} / w$ of $\mathrm{GrC}$ applied to the same surface are released into the environment. 


\section{Results and Discussion}

Environmental Analysis

Figure 3 describes the environmental performance associated with the consumption of $10.8 \mathrm{~kg}$, i.e., the reference flow (RF), calculated to cover $50 \mathrm{~m}^{2}$ of smooth surface outside a building using WP-StC and WP-GrC.

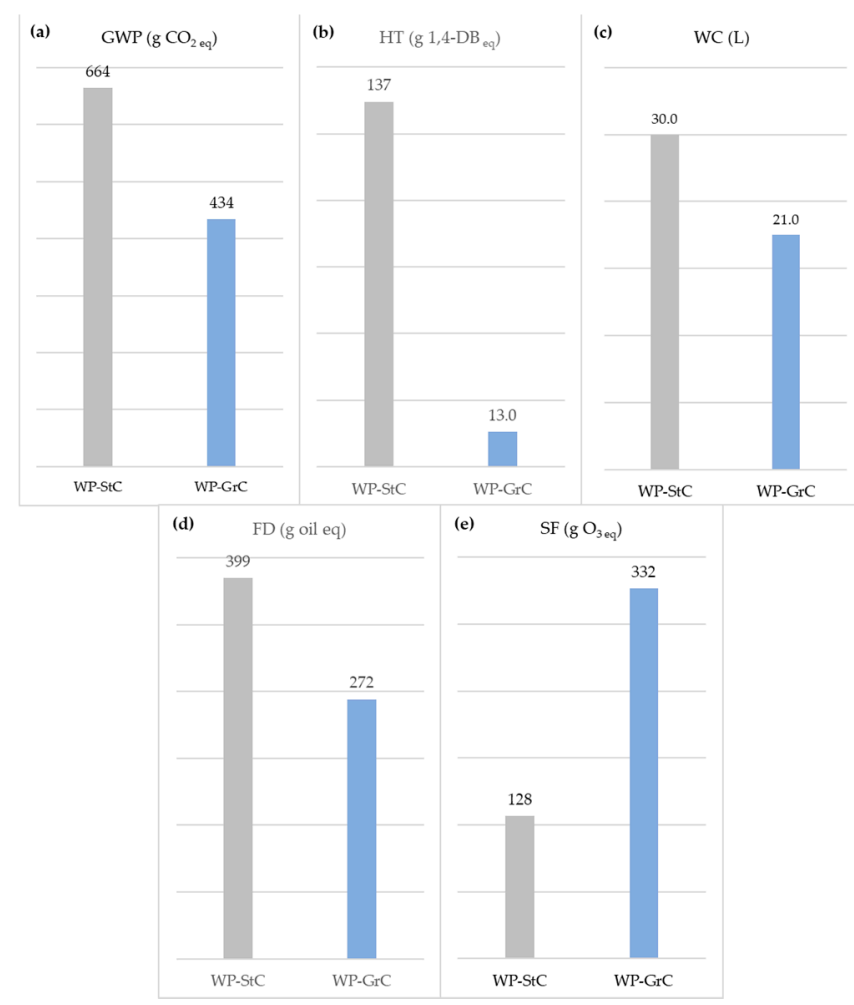

Figure 3. Environmental performance profile of the application of $10.8 \mathrm{~kg}$ (RF) of WP-StC and WP-GrC: (a) global warming potential (GWP); (b) human toxicity (HT); (c) water consumption (WC); (d) fossil depletion (FD); (e) smog formation (SF).

The results indicate that replacing StC with $\mathrm{GrC}$ would be advantageous for most of the investigated impact categories as gains ranging between $30 \%$ for water consumption (WD) and 91\% for human toxicity (HT) would be observed. The exception comprised smog formation (SF), for which the coalescent modification increased the total impact by $159 \%$ in relation to the traditional product performance. The adverse effects in terms of the global warming potential (GWP) associated with WP-StC are mainly due to the consumption of electrical energy (31\%), both for the StC synthesis and paint production. These contributions originate from the fossil nature of the US grid, which is based on thermoelectric energy, comprising coal and derivatives (38\%), as well as natural gas $(27 \%)$ and nuclear energy (19\%) [52].

Isobutyraldehyde processing also contributes to GWP $(26 \%)$ as the thermal demand of the process is met by natural gas and light fuels, which, when burned, result in the emission of $179 \mathrm{~g} / \mathrm{RF}$ of fossil carbon dioxide $\left(\mathrm{CO}_{2, \mathrm{f}}\right)$. Heat generation for the StC synthesis is also noted among the impact sources for this category. Although less than others, this process still emits $28.6 \mathrm{~g} \mathrm{CO}_{2, \mathrm{f}} / \mathrm{RF}$, once again, due to natural gas burning. Finally, the benefits that WP-StC could provide in terms of GWP due to $\mathrm{CO}_{2}$ uptake $\left(4.43 \mathrm{~g} \mathrm{CO}_{2 \text { eq }} / \mathrm{RF}\right)$ were dampened by biogenic carbon dioxide $\left(\mathrm{CO}_{2, \mathrm{~b}}\right)$ air emissions as the biomass that integrates the US grid (1.36\%) [52] corresponds, simultaneously, to $\mathrm{CO}_{2}$ fixation and emission sources.

For the WP-GrC paint, GWP impacts are associated with obtaining the raw materials and inputs consumed in the coalescent preparation. Phenol, whose classic manufacturing route is based on propylene $\left(\mathrm{C}_{3} \mathrm{H}_{6}\right)$ and benzene $\left(\mathrm{C}_{6} \mathrm{H}_{6}\right)$ consumption, is noteworthy in 
this context [54]. If manufacturing $\mathrm{C}_{3} \mathrm{H}_{6}$ brings a $52.1 \mathrm{~g} \mathrm{CO}_{2}$ eq $/ \mathrm{RF}$ share to the total GWP, processing $\mathrm{C}_{6} \mathrm{H}_{6}$ proves to be even more impactful by attributing $117 \mathrm{~g} \mathrm{CO}_{2}$ eq $/ \mathrm{RF}$. Manufacturing ethylene $\left(\mathrm{C}_{2} \mathrm{H}_{4}\right)$ employed in the synthesis of $\mathrm{C}_{2} \mathrm{H}_{4} \mathrm{O}$ adds up another $65.1 \mathrm{~g} \mathrm{CO}_{2}$ eq $/ \mathrm{RF}$. Finally, even though it is carried out by rail, the transfer of $\mathrm{GrC}$ to the paint manufacturing plant adds $10.3 \mathrm{~g} \mathrm{CO}_{2 \text { eq }} / \mathrm{RF}$ to the GWP impacts due to the traveled distance $(4496 \mathrm{~km})$ and the fact that freight trains run on diesel in that region. Furthermore, the gains from $\mathrm{CO}_{2}$ uptake $\left(1.98 \mathrm{~g} \mathrm{CO}_{2} \mathrm{eq} / \mathrm{RF}\right)$ due to the presence of the biomass in the US grid are neutralized by $\mathrm{CO}_{2, b}$ emissions emanating from the burning of this fuel at thermoelectric plants.

Crude oil and natural gas extraction is noteworthy among the human toxicity (HT) sources for both investigated systems. These operations result in barium release into the water (119 g 1,4-DB eq/RF for WP-StC and $9.56 \mathrm{~g}$ 1,4-DB eq/RF in the case of WP$\mathrm{GrC}$ distributed throughout their respective manufacturing cycles). The StC production interferes with the paint performance of which it is an integral part as oil and gas are raw materials used to produce $\mathrm{C}_{2} \mathrm{H}_{4}$ that originates isobutyraldehyde. WP-GrC, on the other hand, receives additional contributions for HT (2.21 g 1,4-DB eq / RF) due to the MX grid characteristics, comprising 56\% natural gas and $16 \%$ oil and derivatives [52].

The water consumption (WC) of WP-StC is directly influenced by the production of isobutyraldehyde. In this process, water regulates the reactor temperature and acts on the distillation tower condensers in which $\mathrm{C}_{4} \mathrm{H}_{8} \mathrm{O}$ is separated from other coproducts, as well as in heat exchangers placed in the plant to adjust fluid temperature [55,56]. Given the exothermic character of the arrangement, the water make-up of isobutyraldehyde synthesis contributes $21.3 \mathrm{~L} / \mathrm{RF}$ to paint $\mathrm{WC}$, with the addition of $4.05 \mathrm{~L} / \mathrm{RF}$ of industrial water used as the diluent in the paint formulation and another $209 \mathrm{~g} /$ FR consumed to replace cold utility losses in the StC production.

Concerning the WP-GrC paint, the main WC precursors are produced in the phenol production chain to obtain cumene $\left(\mathrm{C}_{9} \mathrm{H}_{12}\right)$ and benzene. In these cases, water demand takes place due to purge replacements in the steam generation system boiler and pipes, which correspond to $3.36 \mathrm{~L} / \mathrm{RF}$ and $5.67 \mathrm{~L} / \mathrm{RF}$ for the production of $\mathrm{C}_{9} \mathrm{H}_{12}$ and $\mathrm{C}_{6} \mathrm{H}_{6}$, respectively. Finally, the water incorporated into the product represents $21 \%$ of the WP-GrC WC impacts.

Consumption of raw natural gas for electricity (US grid) and heat supplies and as a source of raw material in the manufacturing of $\mathrm{C}_{3} \mathrm{H}_{6}$ makes up $35 \%$ of the accumulated WP-StC impacts in terms of fossil depletion (FD). Crude oil extraction accounts for another $18 \%$ in this category as it generates heavy oil from which carbon monoxide (CO) is obtained, used as an input for isobutyraldehyde processing. The main FD contributions to WP-GrC are, once again, caused by cumene $(20 \%)$ and benzene $(36 \%)$ production due to natural gas burning to meet thermal demands. The $\mathrm{C}_{2} \mathrm{H}_{4} \mathrm{O}$ production chain collaborates with $24 \%$ of the impact as the synthesis of $\mathrm{C}_{2} \mathrm{H}_{4}$ occurs mainly via steam cracking of short- and medium-chain saturated hydrocarbons. In addition to being the main source of ethane $\left(\mathrm{C}_{2} \mathrm{H}_{6}\right)$ production and a frequent raw material in the production of $\mathrm{C}_{2} \mathrm{H}_{4}$, natural gas acts as a heat provider for steam cracking, which, in order to be effective, must operate at $750-950{ }^{\circ} \mathrm{C}[57]$.

Finally, the results obtained concerning the smog formation (SF) effect were surprising. If, on the one hand, the atmospheric emissions of StC $\left(90 \%_{\mathrm{w} / \mathrm{w}}\right)$ surpassed those of $\mathrm{GrC}$ $\left(52 \%{ }_{\mathrm{w}} / \mathrm{w}\right)$, on the other hand, the disparity between the impact factors of the coalescents of $80.1 \mathrm{~g} \mathrm{O}_{3}$ eq $/ \mathrm{kg} \mathrm{StC}$ and $4.49 \mathrm{~kg} \mathrm{O}_{3}$ eq $/ \mathrm{kg} \mathrm{GrC}$, respectively, is, frankly, favorable to the first asset. As the SF contributions of both paints are concentrated in the use stage of their respective life cycles, the synergy between these effects justifies the inferior performance of WP-GrC in relation to its counterpart for this category.

Given the original expectations surrounding GrC of comprising a molecule with a lower SF potential than the existing marketed compound, the team understood that the project's objective was not achieved. Faced with this finding, instead of following the original plan and verifying the magnitude of the coalescent's participation in the 
accumulated economic performance of WP-GrC, the specialists opted for another path. Therefore, another development cycle began in search of what became the green coalescent alternative (AGrC). AGrC is a branched alcohol ester capable of surpassing StC in terms of smog formation without compromising the technical and environmental performance achieved by $\mathrm{GrC}$ for the other categories analyzed.

\section{Alternative Green Coalescent (AGrC) Design and Performance Evaluation}

\subsection{AGrC Molecule Redesign}

Following the criteria adopted for $\mathrm{GrC}$, the AGrC design also used the design for environment concepts to establish and implement actions to reduce the consumption of resources and emissions throughout its entire life cycle. In practical terms, such interventions took place at three levels: (i) improving the energy efficiency of the coalescent production chain; (ii) closing internal process circuits for the reuse of raw materials; and, perhaps more importantly and prior to these, (iii) designing a molecule whose atmospheric losses during paint application are similar to those achieved by $\mathrm{GrC}$, with a potential smog formation contribution (i.e., impact factor) similar to that of StC.

By overlapping these requirements, technicians converged on a three-stage route. First, a dicarboxylic acid of synthetic origin is esterified by reacting with a branched natural alcohol. As with the GrC synthesis, the transformation takes place in a noncontinuous reactor. The presence of a selective acid catalyst reduces the activation energy of the reaction and makes it less demanding in terms of temperature and pressure. In the second step, excess reagents are separated from AGrC by filtration. Finally, an inorganic silicate is added to the medium to absorb acidic agents and other impurities. The arrangement is completed with a product finishing step that comprises the cooling operations (by indirect contact with water) and AGrC filling (Table 6).

Table 6. Regular operating conditions for the synthesis of AGrC.

\begin{tabular}{ccc}
\hline Process Step & Equipment/Parameter & Specification/Average Value \\
\hline & reaction vessel & Batch (transient state) \\
& cooling system & indirect \\
Reaction & cooling fluid & water \\
& $\mathrm{T}\left({ }^{\circ} \mathrm{C}\right)$ & $110-140$ \\
& $\mathrm{P}(\mathrm{bar})$ & $1.0-2.0$ \\
& $\eta(\%)$ & $70+$ \\
\hline \multirow{2}{*}{ Separation } & filtration & filter bed \\
& $\mathrm{T}\left({ }^{\circ} \mathrm{C}\right)$ & 120 (max.) \\
\hline Finishing & $\mathrm{T}\left({ }^{\circ} \mathrm{C}\right)$ & $<50$ \\
\hline
\end{tabular}

Legend: T: temperature; P: pressure; $\eta$ : theoretical yield.

Other dividends observed in the arrangement reside in the reuse practices associated with the synthesis of AGrC, which avoid material losses, and in the rational use of utilities (i.e., heat and electricity) resulting from the energy integration with other processes in the same industrial complex where the plant is installed. On the other hand, the manufacturing of assets consumes a lot of energy, especially concerning thermal demands. To determine its environmental performance, this process and some of its intermediates were described based on the primary data to build a consistent, detailed, and harmonious model for those developed for StC and GrC. Table 6 depicts the operational conditions assumed to model the AGrC synthesis to determine its environmental and economic performance.

\subsection{Comparison of Environmental Performance of StC vs. GrC vs. AGrC}

The environmental performance of AGrC was also indirectly investigated via the application of a building paint containing this component. To this end, LCA was applied once again in the attributional cradle-to-grave modality. The results were compared to those obtained with WP-StC and WP-GrC. By adopting this strategy, the project team 
sought to measure the behavior of the alternative molecule in relation to that of the standard coalescent at the same time, as well as to explore advances and setbacks regarding previous development.

\subsubsection{Life Cycle Modeling and LCI}

In the second round of LCA application, the list of objects for analysis comprised latex decorative wall paints formulated with the standard coalescent (WP-StC), the green coalescent (WP-GrC), and the alternative green coalescent (WP-AGrC). Other aspects of the scope definition (the functional unit, reference flow, procedures for addressing multifunctional situations, methods, and categories for environmental impact assessment) remained unchanged from the propositions established in Section 3.2. Regarding the product systems, the difference between the paint life cycles lies in the production chains of the coalescents that make up their formulations.

The data that portray the AGrC synthesis in terms of technology, consumption, and emissions were obtained from both primary and secondary sources. The primary data were obtained for 2018-2019, while the secondary data consisted of temporal coverage conditioned to the current LCI character available in the Ecoinvent ${ }^{\circledR}$ database. Regarding geographic coverage, it was assumed that the manufacturing of the coalescent, its raw materials and inputs would take place in Mexico (Guadalajara and Mexico City), Brazil (Mauá, São Paulo State), and China (Anquing, Anhui Province), the WP-AGrC formulation and application-in McCarran (in the same way as for WP-StC and WP-GrC).

The LCI describing the processing of $1.0 \mathrm{~kg}$ of AGrC is indicated in Table 7. Phosphorus oxyacid and sulfonic acid transports were modeled considering a common supplier that delivers the assets using roads from Mexico City to Guadalajara (547 km). Magnesium silicate would originate from Texas and reach Guadalajara after traveling $1421 \mathrm{~km}$ by sea and another $1208 \mathrm{~km}$ by truck. The dicarboxylic acid supplier would be located in Anquing, so an arrangement consisting of a maritime mode $(13,132 \mathrm{~km})$ was defined for this transfer, followed by road transport $(324 \mathrm{~km})$. The branched alcohol is generated in Mauá and follows a similar route to that of the organic acid until reaching the coalescent production unit, covering $10,043 \mathrm{~km}$ by cargo ship and $1225 \mathrm{~km}$ by road. The data describing the Chinese and Mexican electrical matrices were obtained from the Ecoinvent ${ }^{\circledR}$ database and updated for 2015 [52]. These adjustments made the AGrC production cycle consistent with the conditions adopted for StC and GrC regarding this utility. Finally, it was established that steam generation at the Guadalajara plant would take place from natural gas combustion.

Table 7. Raw material and input consumption for the production of $1.0 \mathrm{~kg}$ of AGrC.

\begin{tabular}{cc}
\hline & Inputs \\
\hline Material Inputs & Amount \\
\hline Phosphorus oxyacid $(\mathrm{g})$ & $1.00-4.00$ \\
Dicarboxylic acid $(\mathrm{g})$ & $300-500$ \\
Branched alcohol $(\mathrm{g})$ & $700-900$ \\
Magnesium silicate $(\mathrm{g})$ & $10.0-19.0$ \\
Organic sulfonic acid $(\mathrm{g})$ & $1.00-3.00$ \\
Cooling water, make-up $(\mathrm{g})$ & $1.00-2.00$ \\
\hline Energy Inputs & Amount \\
\hline Steam $(\mathrm{kg})$ & $0.30-1.50$ \\
Electricity $(\mathrm{kWh})$ & $0.10-0.50$ \\
\hline & Outputs \\
\hline Material Outputs & Amount \\
\hline Coalescent AGrC $\left(98.5 \%{ }_{\mathrm{w}} / \mathrm{w}\right)(\mathrm{kg})$ & 1.00 \\
\hline
\end{tabular}

The manufacturing of WP-AGrC was modeled in a similar way to WP-StC and WPGrC using the manufacturer's data. Thus, AGrC travels $3114 \mathrm{~km}$ from Guadalajara to 
McCarran by road. Finally, the WP-AGrC application employed the previous modeling standards, getting restricted in terms of environmental loads to coalescent emissions. The laboratory tests carried out for the established conditions study concluded that $50 \%_{\mathrm{w} / \mathrm{w}}$ of AGrC applied with the decorative paint would be released into the atmosphere.

\subsubsection{Comparison of Environmental Performance}

Figure 4 describes the environmental profiles of the investigated paint for the reference flow considered herein, where the findings indicate that WP-AGrC prevails over the other options in almost all impact-evaluated categories. The exception was the human toxicity category, which, despite surpassing that obtained with WP-StC by about $72 \%$, proved to be threefold more aggressive than that obtained with WP-GrC.

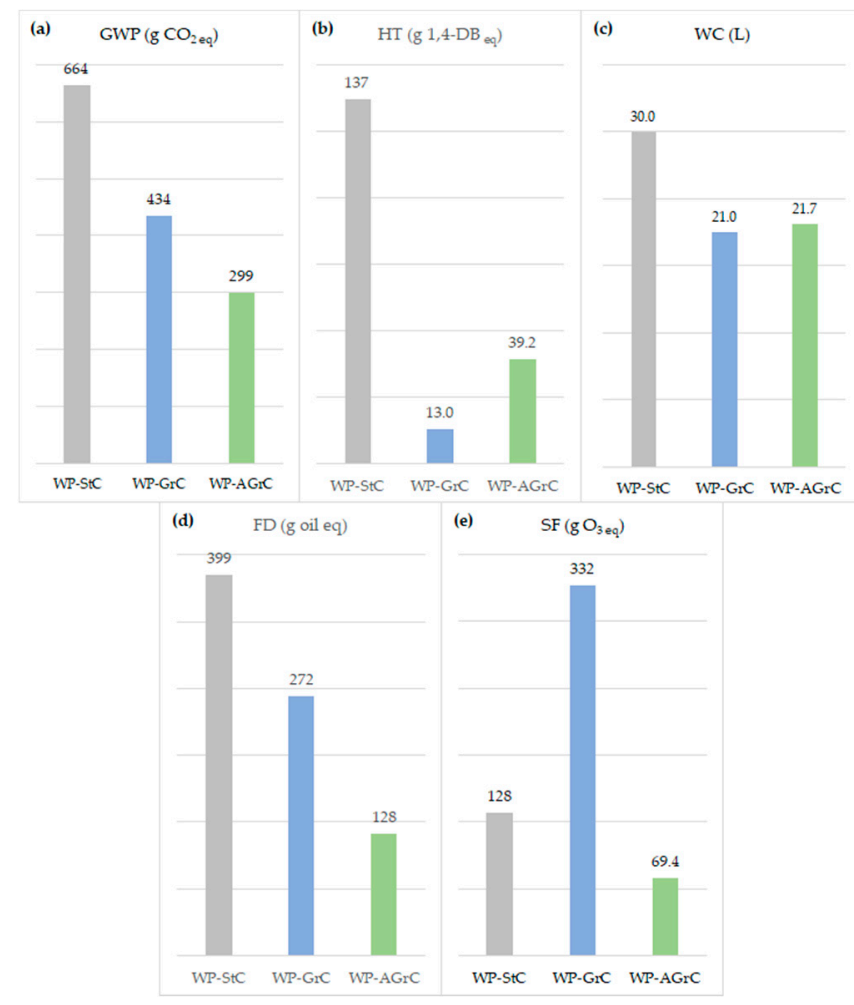

Figure 4. Environmental profile associated with the application of $10.8 \mathrm{~kg}$ (RF) of WP-StC, WPGrC, and WP-AGrC: (a): global warming potential (GWP); (b): human toxicity (HT); (c): water consumption (WC); (d): fossil depletion (FD); (e): smog formation (SF).

Concerning GWP, the total impacts of the paint containing AGrC were, respectively, $55 \%$ and $31 \%$ lower than those produced with StC and GrC. The main individual contribution of WP-AGrC to this category resides in $\mathrm{CO}_{2}$ emissions originating from land transformation $\left(\mathrm{CO}_{2, \mathrm{LT}}\right)\left(133 \mathrm{~g} \mathrm{CO}_{2, \mathrm{eq}} / \mathrm{RF}\right)$ due to the expansion of sugarcane over areas originally occupied by other crops. This effect reverberates on the overall performance of the paint as the branched alcohol that serves as a raw material in the AGrC synthesis originates from fusel oil, a byproduct of bioethanol processing. Another impact focus for GWP refers to the burning of tail gas from carbon black processing $\left(76.4 \mathrm{~g} \mathrm{CO}_{2, \mathrm{eq}} / \mathrm{RF}\right)$ for the production of steam consumed during alcohol synthesis. Finally, obtaining maleic anhydride $\left(\mathrm{C}_{4} \mathrm{H}_{2} \mathrm{O}_{3}\right)$, an essential input for the manufacturing of dicarboxylic acid, comprises another significant source of global warming contribution. The typical manufacturing route for $\mathrm{C}_{4} \mathrm{H}_{2} \mathrm{O}_{3}$ via catalytic benzene oxidation contributes with $91.7 \mathrm{~g} \mathrm{CO}_{2, \mathrm{eq}} / \mathrm{RF}$, with $73 \%$ of this total generated in the synthesis per se, and the remainder originating from the production of $\mathrm{C}_{6} \mathrm{H}_{6}$. The presence of a renewable asset in the production cycle was decisive for the $\mathrm{AGrC}$ results in relation to GWP. The use of fuel oil allowed for a $\mathrm{CO}_{2}$ uptake rate originating from sugarcane cultivation ( $\left.461 \mathrm{~g} \mathrm{CO}_{2, \mathrm{eq}} / \mathrm{RF}\right)$ capable of absorbing 
inputs derived from $\mathrm{CO}_{2, \mathrm{~b}}$ emissions from biomass combustion in the field and from the generation of heat and electricity used in the distillery to reach $222 \mathrm{~g} \mathrm{CO}_{2, \text { eq }} / \mathrm{RF}$ in total. $\mathrm{CO}_{2}$ fixation from the air by sugarcane resulted in a large surplus effect on the performance of WP-AGrC due to the non-existence of end-of-life emissions that derive from this biological process, which are also considered when applying the IPCC 2013 100a method including $\mathrm{CO}_{2}$ uptake. A portion of the carbon from sugarcane that reaches the AGrC composition via fusel oil is released into the air as part of this structure, immobilized, and, therefore, prevented from acting as a greenhouse gas. The remainder of $C$ captured during photosynthesis remains an integral part of the paint, keeping adhered to the area over which it is applied. This condition also blocks the forcing of infrared radiation towards Earth's surface. If the presence of an asset of agricultural and renewable origin in the AGrC processing cycle slows down the paint's performance in terms of GWP, the same cannot be said about its participation in HT. In this case, the total losses to soil of crop protection products (i.e., $2.4 \mathrm{D}$, atrazine, glyphosate and linuron) used in pest control by sugarcane cultivation generated a contribution of $11.1 \mathrm{~g} 1,4-\mathrm{DB}$ eq $/ \mathrm{RF}$, or $28 \%$ of the total impact for the category.

In addition, release of cadmium and arsenic, the micronutrients applied to this crop to increase productivity, contributed with another 2.84 and $1.18 \mathrm{~g} 1,4-\mathrm{DB}$ eq/RF. The group of great human toxicity precursors associated with WP-AGrC comprise barium and arsenic water emissions due to onshore oil and raw natural gas crude oil extraction and whose

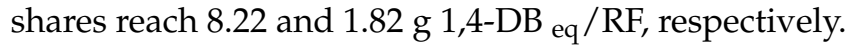

Even surpassing the paint produced with the conventional coalescent by $28 \%$, the WP-AGrC performance remained at the level achieved by WP-GrC regarding WC. In this category, the alternative paint received contributions from three sources. The first, associated to the branched alcohol, comprises the most expressive sources of impact in the form of sugarcane plantation irrigation $(11.3 \mathrm{~L} / \mathrm{RF})$ and industrial fusel oil production $(1.72 \mathrm{~L} / \mathrm{RF})$. Dicarboxylic acid contributes with $2.82 \mathrm{~L} / \mathrm{RF}$, of which the synthesis of $\mathrm{C}_{4} \mathrm{H}_{2} \mathrm{O}_{3}$ and $\mathrm{C}_{6} \mathrm{H}_{6}$ accounts for $52 \%$ and $41 \%$, respectively. Finally, the paint formulation itself represents another water consumption source due to the incorporation of $4.58 \mathrm{~L} / \mathrm{RF}$ to meet the average amount of thinner established by its manufacturing recipe (Table 3 ).

The WP-AGrC performance with respect to FD outperformed those achieved by WP-StC and WP-GrC by $68 \%$ and $53 \%$. As already noted for the previous cases, the consumption of crude oil and raw natural gas to produce the fuels used to generate electrical and thermal energy for machine movement and in transport operations are the main impact precursors in this scope. However, as AGrC is produced under ambient conditions and the utilities consumed in obtaining the fusel oil are provided by the sugarcane biomass (i.e., bagasse, straw, and tip), the demands of those fossil resources were naturally reduced. The impact of the alternative paint associated with crude oil was $86.0 \mathrm{~g}$ oil eq/RF, about $47 \%$ lower than that of the standard and green paint, and the input of raw natural gas of $29.0 \mathrm{~g}$ oil eq/RF was even more effective for FD, surpassing the WP-StC and WP-GrC values by $84 \%$ and $69 \%$.

The success achieved by WP-AGrC with respect to smog formation is due to the coalescent emission levels when applying the paint and the degree of danger of this molecule for the category. Concerning emission rates, AGrC presented an equivalent performance to that calculated for $\mathrm{GrC}$ and almost twice as small as that for StC. However, the most expressive advance of the alternative molecule is linked to its potential for smog formation ( $60.0 \mathrm{~g} \mathrm{O}_{3}$ eq $/ \mathrm{kg}$ coalescent), $25 \%$ lower than that associated with $\mathrm{StC}$ and 75 -fold lower than that observed for $\mathrm{GrC}$. Apart from this result, nitrogen oxide $\left(\mathrm{NO}_{\mathrm{x}}\right)$ atmospheric emissions caused by the burning of sugarcane bagasse at the plant when producing fusel oil continue to contribute to the SF effect of WP-AGrC $\left(8.40 \mathrm{~kg} \mathrm{O}_{3} \mathrm{eq} / \mathrm{RF}\right)$, in the branched alcohol transport cycles from Mauá ( $6.30 \mathrm{~kg} \mathrm{O}_{3} \mathrm{eq} / \mathrm{RF}$ ), the dicarboxylic acid journey from Anquing ( $3.19 \mathrm{~kg} \mathrm{O}_{3}$ eq $/ \mathrm{RF}$ ) to Guadalajara, and in the rail journey of AGrC to McCarran. These results suggest that a review of the input distribution logistics of the WP-AGrC processing can bring an additional impact decrease to the smog formation effect. 


\subsubsection{Economic Analysis}

After confirming AGrC's environmental supremacy over StC, the project team followed the originally established plan and analyzed the economic performance analysis of the alternative coalescent. The development of this estimate was based on three premises: (i) verification of the economic performance of $\mathrm{AGrC}$ would occur from the comparison of its result in that dimension, with the correspondents obtained by $\mathrm{StC}$ and $\mathrm{GrC}$; (ii) the specialists defined the final price of each product as the performance indicator to be considered in the analysis; and (iii) the economic analysis must have a scope compatible with the one adopted for the environmental analysis so that the results of both dimensions could be associated. The final price was chosen as the economic indicator because its composition considers direct and indirect production costs, fixed expenses, contribution margin, competition, markup, and profit margin, which attribute representativeness and completeness to the index.

The economic profile of StC was characterized by the minimum and maximum values of coalescent prices obtained from companies in the paint segment between 2018 and 2019. On the other hand, the manufacturer of $\mathrm{GrC}$ and $\mathrm{AGrC}$ prepared projections to determine their price limits because the products were not established on the market.

Table 8 presents the price ranges for each investigated coalescent. Detailing the indicators under the most favorable conditions of direct and indirect costs without affecting the company's profit margin, $\mathrm{GrC}$ and $\mathrm{AGrC}$ could be traded at prices below $10 \%$ and $5.0 \%$ of the minimum value practiced for StC between 2018 and 2019. Furthermore, under the same circumstances, AGrC is about 5.6\% more expensive than GrC. On the other hand, values are equalized at the upper end of the ranges.

Table 8. Minimum and maximum price values for StC, GrC, and RGrC for the 2018-2019 biennium.

\begin{tabular}{ccc}
\hline Coalescent & $\begin{array}{c}\text { Minimum Specific Price } \\
\left(\mathbf{U S D} / \mathbf{k g}^{-\mathbf{1})}\right.\end{array}$ & $\begin{array}{c}\text { Maximum Specific Price } \\
\left(\mathbf{U S D} / \mathbf{k g}^{-\mathbf{1})}\right.\end{array}$ \\
\hline StC & 1.80 & 1.98 \\
$\mathrm{GrC}$ & 1.62 & 1.98 \\
$\mathrm{AGrC}$ & 1.71 & 1.98 \\
\hline
\end{tabular}

This scenario suggests three interpretations. First, the strategy adopted to design less environmentally aggressive coalescents made these assets more competitive than $\mathrm{StC}$, at least in floor prices. Second, the search to reduce the impacts of smog formation associated with $\mathrm{GrC}$ led to an increase in the minimum price of AGrC, creating, in this case, a dichotomy between the economic and environmental dimensions.

Finally, it is clear that if the price of products reaches its extreme limit, the paint industry will favor this dimension whenever it does not identify a significant technical performance discrepancy between the coalescents. With this, at least in theory, the environmental attribute would lose importance or not be considered. This finding suggests that only market aspects (i.e., strategy and maintenance and competition for market niches) regulate prices in this segment.

\subsubsection{Ecoefficiency Analysis (EEA)}

The last of the activities foreseen in the project consisted in the elaboration of an ecoefficiency analysis (EEA) with the purpose of investigating effects resulting from the integration between the environmental and economic performance of the developed coalescent. Originally, this was supposed to include only StC and $\mathrm{AGrC}$, but the fact that $\mathrm{GrC}$ was surpassed by the standard coalescent in the environmental domain only in smog formation and because it has the lowest minimum limit of the price range of the entire asset series made this alternative considered once more.

Conceptually, EEA conducted in this study is a variant of the approach proposed in [58] in which the environmental and economic performance of one of the analysis scenarios (or objects) are used as references for applying the standardization procedure. This 
logic was applied previously for assessments in water recovery areas [59-61], beef production [62], solid waste management [43], and energy resources [63], providing consistent results. As it has been on the market for years, StC has naturally become this standard for the present case. Thus, the individual results obtained by $\mathrm{GrC}$ and $\mathrm{AGrC}$ for each impact category considered during the environmental analysis were divided by the performance values that corresponded in the respective items. The operation produced dimensionless indices that, when summed, generated specific cumulative environmental indicators for each coalescent $\left(\mathrm{EI}_{\mathrm{i}}\right)$. Finally, another normalization from the division between $\mathrm{EI}_{\mathrm{i}}$ and $\mathrm{EI}_{\mathrm{StC}}$ determined the standardized environmental performance indicator $\left(\mathrm{SEI}_{\mathrm{i}}\right)$ of each coalescent.

A very similar approach was used for the standardized economic performance Indicator of solvents, which, due to the fact that their prices were described in the form of a range of variation, were estimated for the minimum $\left(\mathrm{S} \$ \mathrm{IMin}_{i}\right)$ and maximum $\left(\mathrm{S} \$ \mathrm{IMax}_{\mathrm{i}}\right)$ limits from those intervals. Furthermore, as the economic analysis generated a consolidated indicator, the normalization procedure was summarized by dividing the minimum $\left(\$ \mathrm{IMin}_{\mathrm{i}}\right)$ and maximum $\left(\$ \mathrm{IMax}_{\mathrm{i}}\right)$ prices of each analyzed coalescent by the corresponding values for StC ( $\$ \mathrm{IMin}_{\mathrm{StC}}$ and $\$ \mathrm{IMax}_{\mathrm{StC}}$ ). Table 9 presents the intermediate and final results of the standard performance indicator elaboration process of all the coalescents for the environmental and economic dimensions.

Table 9. Creation of SEI, S\$IMin, and S\$IMax values for StC, GrC, and AGrC.

\begin{tabular}{|c|c|c|c|c|}
\hline \multicolumn{5}{|c|}{ Standardized Environmental Performance Indicator $\left(\mathrm{SEI}_{\mathrm{i}}\right)$} \\
\hline Impact Category & Unit (/RF) & StC & GrC & AGrC \\
\hline GWP & $\mathrm{g} \mathrm{CO}_{2 \mathrm{eq}}$ & 664 & 434 & 299 \\
\hline HT & g $1,4-\mathrm{DB}$ eq & 137 & 13 & 39.2 \\
\hline WC & $\mathrm{L}$ & 30 & 21 & 21.7 \\
\hline FD & $\mathrm{g}$ oil eq & 399 & 272 & 128 \\
\hline SF & $\mathrm{g} \mathrm{O}_{3}$ eq & 128 & 332 & 69.4 \\
\hline Impact Category & Unit & StC & GrC & AGrC \\
\hline $\mathrm{N}_{\mathrm{GWP}}$ & - & 1.00 & 0.65 & 0.45 \\
\hline $\mathrm{N}_{\mathrm{HT}}$ & - & 1.00 & 0.09 & 0.29 \\
\hline $\mathrm{N}_{W C}$ & - & 1.00 & 0.70 & 0.72 \\
\hline $\mathrm{S}_{\mathrm{FD}}$ & - & 1.00 & 0.68 & 0.32 \\
\hline $\mathrm{S}_{\mathrm{SF}}$ & - & 1.00 & 2.59 & 0.54 \\
\hline $\mathrm{EI}_{\mathrm{i}}$ & - & 5.00 & 4.72 & 2.32 \\
\hline $\mathrm{SEI}_{\mathrm{i}}$ & - & 1.00 & 0.94 & 0.46 \\
\hline \multicolumn{5}{|c|}{ Standardized Economic Performance Indicator $\left(\mathbf{S} \$ \mathbf{I}_{\mathbf{i}}\right)$} \\
\hline Price & Unit (/RF) & $\mathrm{StC}$ & GrC & AGrC \\
\hline SIMin $_{\mathrm{i}}$ & USD & 0.23 & 0.21 & 0.22 \\
\hline 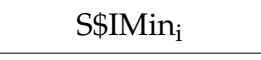 & - & 1.00 & 0.90 & 0.95 \\
\hline \$IMax $_{\mathrm{i}}$ & USD & 0.26 & 0.26 & 0.26 \\
\hline S\$Max $_{i}$ & - & 1.00 & 1.00 & 1.00 \\
\hline
\end{tabular}

According to [58], the degree of ecoefficiency of the studied objects corresponds to the locus determined by their coordinates (S\$I; SEI) in a two-dimensional system of axes with the maximum scale equal to unity. The limit and hypothetical conditions would be the origin of the axes at coordinate [0;0]. Figure 5a,b describes the behavior of the investigated coalescents according to this perspective, with \$IMin and \$IMax placed on the ordinates. The findings indicate that AGrC prevails over the other coalescents regardless of whether $\mathrm{S} \$ \mathrm{I}$ is estimated for the minimum or maximum values. This result is mainly due to the environmental performance accumulated by the alternative coalescent. On the other hand, even though $\mathrm{GrC}$ surpassed the other coalescents in terms of S\$IMin (Figure 5a), the 
result obtained in terms of smog formation $\left(\mathrm{SEI}_{\mathrm{GrC}}\right)$ so negatively influenced its global environmental performance that the gains obtained in the other impact categories were not able to reverse the situation even when summed, even though the performance in terms of human toxicity was the best in the entire investigated series.

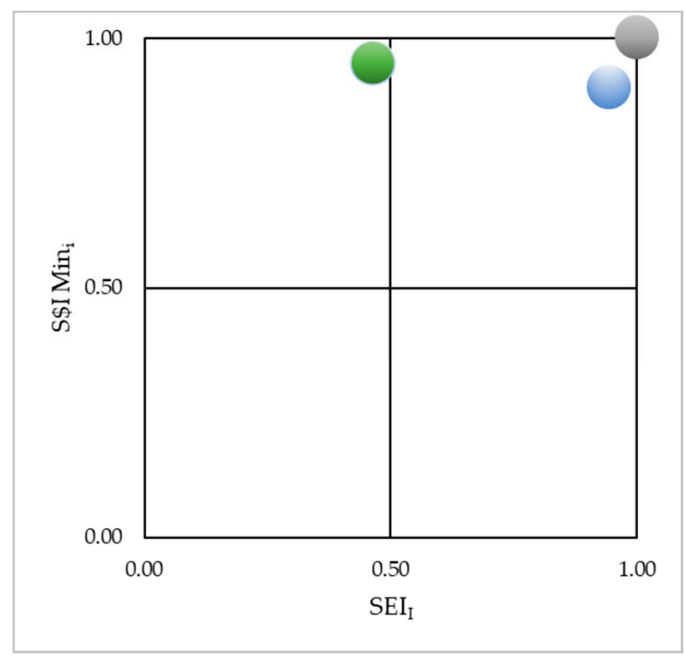

(a)

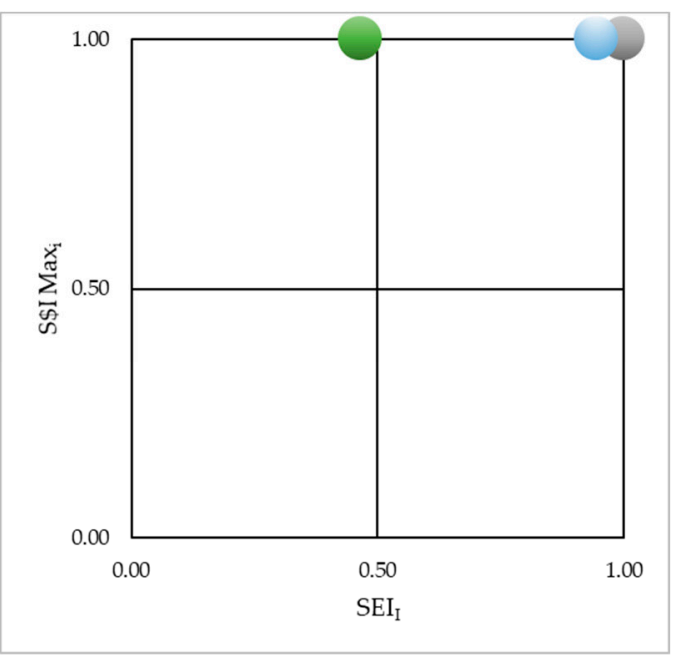

(b)

Figure 5. Ecoefficiency assessment diagram for the StC, GrC, and AGrC coalescents considering: (a) Minimum values of Standardized economic performance indicator; and (b) Maximum values of Standardized economic performance indicator.

When the ecoefficiency of the coalescents was estimated for the maximum price conditions (Figure $5 b$ ), the equity between the $\mathrm{S} \$ \mathrm{I}$ values limited the comparison to the products' accumulated environmental performance, indicating that $\mathrm{GrC}$ and StC were similar options.

Finally, it should be noted that one of the most important merits of designing a coalescent molecule using the DfE practices is the fact that GrC and AGrC remained competitive in terms of technical performance and price in relation to $\mathrm{StC}$, even though the initiative's efforts were focused on improving the environmental profile of those compounds.

\section{Conclusions}

This study aimed to design a coalescent for decorative paints that would reach technical levels equivalent to those obtained by $\mathrm{StC}$, a product on the market, but with better environmental and economic performance. The strategy adopted in creating the green coalescent $(\mathrm{GrC})$ improved film formation and reduced the product's atmospheric emission rate due to its high boiling point $\left(>250^{\circ} \mathrm{C}\right)$.

In terms of environmental performance, $\mathrm{GrC}$ outperformed $\mathrm{StC}$ in terms of water consumption, global warming potential, and human toxicity by $30 \%, 35 \%$, and $91 \%$, respectively. These results are due to the technology and raw materials (ethylene oxide and phenol) involved in the synthesis of $\mathrm{GrC}$, which are less aggressive than those used to obtain StC, a derivative of isobutyraldehyde. On the other hand, $\mathrm{GrC}$ has a very high smog formation potential, being around 1.5 times more impactful than StC in this category, even with a lower loss to the air. The redesign of the molecule gave rise to $\mathrm{AGrC}$ which, derived from renewable alcohol and dicarboxylic acid, prevailed over StC and GrC in terms of smog formation without seriously compromising the environmental performance in other investigated impact categories.

The results of the economic analysis indicated that the procedures adopted to project $\mathrm{GrC}$ and $\mathrm{AGrC}$ made these assets also more competitive than StC when the lowest market prices are practiced. On the other hand, the search to reduce the impacts of smog formation raised the minimum price of $\mathrm{AGrC}$ compared to that of $\mathrm{GrC}$, creating a dichotomy between the economic and environmental dimensions. Finally, we observed that if the products 
are sold at the highest market prices, the paint industry tends to privilege the economic dimension whenever the technical equivalence between the coalescents is maintained and disregards the environmental performance for decision purposes.

The performance of an ecoefficiency analysis to investigate the effects of integration between the environmental and economic performance of coalescents only ratified the previous conclusions obtained individually for each product.

The main limitation faced throughout the study was the unavailability of robust parameters in the synthesis of StC. Although the use of literature data and expert guidance has mitigated the problem, a conceptual model was developed in this case. Thus, even if its accuracy meets the exploratory expectations of this phase of the project, it would be desirable to have the primary data to validate the results obtained by the simulations.

Given the results obtained by this study, it is recommended to identify actions that reduce the impacts of $\mathrm{AGrC}$ on human toxicity up to the limits equivalent to those achieved by $\mathrm{GrC}$ without compromising its performance in other impact categories. Another possibility is to design a variant of AGrC derived from a renewable carboxylic acid. However, this molecule must have its environmental performance carefully investigated since the production of agricultural actives predisposes to the use of agrochemicals whose toxicity is inherent and quite significant.

Author Contributions: Conceptualization, L.K.; methodology, I.L.C.C. and F.R.; resources, L.K.; data curation, F.R.; writing-original draft preparation, I.L.C.C.; writing-review and editing, L.K. and I.L.C.C.; supervision, L.K. All authors have read and agreed to the published version of the manuscript.

Funding: This research was partially funded by Coordenação de Aperfeiçoamento de Pessoal de Nível Superior-Brazil (CAPES) Finance Code 001.

Data Availability Statement: Not applicable.

Acknowledgments: We gratefully acknowledge the support of Coordenação de Aperfeiçoamento de Pessoal de Nível Superior Brazil (CAPES) Finance Code 001 that was essential for this study to be brought to a conclusion.

Conflicts of Interest: The authors declare no conflict of interest.

\section{References}

1. Levchenko, Y.; Sverdlovsk, O.; Chervakov, D.; Chervakov, O. Development of Coalescents for Paints and Varnishes Based on Ionic Liquids-The Products of Diethanolamine and Inorganic Acids Interaction. East.-Eur. J. Enterp. Technol. 2021, 110, 21-29. [CrossRef]

2. Dehan, V.; Bourgeat-Lami, E.; D’Agosto, F.; Duffy, B.; Fortini, A.; Hilton, S.; Krassa, K.; Keddie, J.K.; Koh, M.L.; Lansalot, M.; et al. High-performance water-based barrier coatings for the corrosion protection of structural steel. Steel Constr. 2017, 10, 254-259. [CrossRef]

3. Kaur, J.; Krishnan, R.; Ramalingam, B.; Jana, S. Hydroxyethyl sulfone based reactive coalescing agents for low-VOC waterborne coatings. RSC Adv. 2020, 10, 17171-17179. [CrossRef]

4. Global Coalescing Agent Report: History, Present and Future (from 2015 to 2025); Prof Research: Portland, OR, USA, 2020; 131p.

5. Santos, J.P.; Nakashima, F.F.; Rosa, F.; Armelin, N.A.; Da Silva AL, C.; Silva, G.A. Green Coalescent Agent Composition Containing Mixtures of Monoesters and Diesters. U.S. Patent No. 9,926,430, 27 March 2018.

6. Taylor, J.W. Acid-Containing Polymers as Coalescing Agents for Latexes. U.S. Patent No. 10,563,084, 18 February 2018.

7. Eastman Chemical Company. Eastman Products for Coating and Ink Formulation. 2021. Available online: https://www.eastman. com/Literature_Center/A/ADDCOAT021.pdf (accessed on 4 November 2021).

8. Berce, P.; Skale, S.; Razborsek, T.; Slemnik, M. Influence of coalescing aids on the latex properties and film formation of waterborne coatings. J. Appl. Polym. Sci. 2017, 134, 45142. [CrossRef]

9. Klähn, M.; Krishnan, R.; Phang, J.M.; Lim, F.C.H.; Van Herk, A.M.; Jana, S. Effect of external and internal plasticization on the glass transition temperature of (Meth)acrylate polymers studied with molecular dynamics simulations and calorimetry. Polymer 2019, 179, 121635. [CrossRef]

10. Colonetti, E.; Rovani, R.; Westrup, J.L.; Cercená, R.; Cargnin, M.; Peterson, M.; Dal-Bó, A.G. Effects of resin/curing agent stoichiometry and coalescence of emulsion particles on the properties of waterborne epoxy coatings upon accelerated weathering. Mater. Chem. Phys. 2022, 275, 125228. [CrossRef] 
11. Dedoussi, I.C.; Eastham, S.D.; Monier, E.; Barrett, S.R.H. Premature mortality related to United States cross-state air pollution. Nature 2020, 578, 261-265. [CrossRef]

12. Hanif, N.M.; Hawari, N.S.S.L.; Othman, M.; Hamid, H.H.A.; Ahamad, F.; Uning, R.; Ooi, M.C.G.; Wahab, M.I.A.; Sahani, M.; Latif, M.T. Ambient volatile organic compounds in tropical environments: Potential sources, composition, and impacts-A review. Chemosphere 2021, 285, 131355. [CrossRef]

13. Suzuki, N.; Nakaoka, H.; Hanazato, M.; Nakayama, Y.; Takaya, K.; Mori, C. Emission rates of substances from low-volatileorganic-compound paints. Int. J. Environ. Sci. Technol. 2019, 16, 4543-4550. [CrossRef]

14. Limousin, E.; Martinez-Tong, D.E.; Ballard, N.; Asua, J.M. Cure-dependent morphology of acrylic/alkyd hybrid latex films via nanomechanical mapping. ACS Appl. Polym. Mater. 2019, 1, 2213-2223. [CrossRef]

15. International Organization for Standardization (ISO). Environmental Management-Life Cycle Assessment-Principles and Framezork, 2nd ed.; ISO 14040:2006; ISO: Geneva, Switzerland, 2006.

16. International Organization for Standardization (ISO). Environmental Management-Life Cycle Assessment-Requirements and Guidelines, 1st ed.; ISO 14044:2006; ISO: Geneva, Switzerland, 2006.

17. Paiano, A.; Gallucci, T.; Pontrandolfo, A.; Lagioia, G.; Piccinno, P.; Lacalamita, A. Sustainable options for paints through a life cycle assessment method. J. Clean. Prod. 2021, 295, 126464. [CrossRef]

18. Upadhyayula, V.K.K.; Meyer, D.E.; Gadhamshetty, V.; Koratkar, N. Screening-level life cycle assessment of graphene-poly (ether imide) coatings protecting unalloyed steel from severe atmospheric corrosion. ACS Sustain. Chem. Eng. 2017, 5, 2656-2667. [CrossRef]

19. Montazeri, M.; Eckelman, M.J. Life cycle assessment of UV-Curable bio-based wood flooring coatings. J. Clean. Prod. 2018, 192, 932-939. [CrossRef]

20. Rossini, P.; Napolano, L.; Matteucci, G. Biotoxicity and life cycle assessment of two commercial antifouling coatings in marine systems. Chemosphere 2019, 237, 124475. [CrossRef]

21. Klug, V.; Schöggl, J.; Dallinger, D.; Hiebler, K. Comparative life cycle assessment of different production processes for waterborne polyurethane dispersions. ACS Sustain. Chem. Eng. 2021, 9, 8980-8989. [CrossRef]

22. Evangelista, P.P.A.; Kiperstok, A.; Torres, E.A.; Gonçalves, J.P. Environmental performance analysis of residential buildings in Brazil using life cycle assessment (LCA). Constr. Build. Mater. 2018, 169, 748-761. [CrossRef]

23. Ansah, M.K.; Chen, X.; Yang, H.; Lu, L.; Lam, P.T.I. An integrated life cycle assessment of different façade systems for a typical residential building in Ghana. Sustain. Cities Soc. 2020, 53, 101974. [CrossRef]

24. Dominguez-Delgado, A.; Domínguez-Torres, H.; Domínguez-Torres, C.-A. Energy and economic life cycle assessment of cool roofs applied to the refurbishment of social housing in southern Spain. Sustainability 2020, 12, 5602. [CrossRef]

25. Trovato, M.R.; Nocera, F.; Giuffrida, S. Life-cycle assessment and monetary measurements for the carbon footprint reduction of public buildings. Sustainability 2020, 12, 3460. [CrossRef]

26. Cherubini, E.; Ribeiro, P.T. Diálogos Setoriais Brasil e União Europeia: Desafios e soluções Para o fortalecimento da ACV no Brasil; Instituto Brasileiro de Informação em Ciência e Tecnologia (IBICT): Brasília, Brazil, 2015.

27. Hansen, A.P.; Silva, G.A.; Kulay, L. Evaluation of the environmental performance of alternatives for polystyrene production in Brazil. Sci. Total Environ. 2015, 532, 655-668. [CrossRef]

28. De Léis, C.M.; Nogueira, A.R.; Kulay, L.; Tadini, C.C. Environmental and energy analysis of biopolymer film based on cassava starch in Brazil. J. Clean. Prod. 2017, 143, 76-89. [CrossRef]

29. Souza, C.G.; Barbastefano, R.G.; Teixeira, R.C. Life cycle assessment research in Brazil: Characteristics, interdisciplinarity and applications. Int. J. Life Cycle Assess. 2017, 22, 266-276. [CrossRef]

30. Moore, C.C.S.; Nogueira, A.R.; Kulay, L. Environmental and energy assessment of the substitution of chemical fertilizers for industrial wastes of ethanol production in sugarcane cultivation in Brazil. Int. J. Life Cycle Assess. 2017, 22, 628-643. [CrossRef]

31. Moore, C.C.S.; Rego, E.; Kulay, L. The Brazilian electricity supply for 2030: A projection based on economic, environmental and technical criteria. Environ. Nat. Resour. J. 2017, 7, 4. [CrossRef]

32. Donke, A.; Nogueira, A.; Matai, P.; Kulay, L. Environmental and energy performance of ethanol production from the integration of sugarcane, corn and grain sorghum in a multipurpose plant. Resources 2017, 6, 1. [CrossRef]

33. Guerra, J.P.; Cardoso, F.H.; Nogueira, A.; Kulay, L. Thermodynamic and environmental analysis of scaling up cogeneration units driven by sugarcane biomass to enhance power exports. Energies 2018, 11, 73. [CrossRef]

34. Nogueira, A.R.; Popi, M.G.C.B.; Moore, C.C.S.; Kulay, L. Environmental and energetic effects of cleaner production scenarios on the sodium lauyl ether sulfate production chain. J. Clean. Prod. 2019, 240, 118203. [CrossRef]

35. Moraes, F.B.M.; Lopes, L.C.; Kulay, L. Proposals for the redesign of mouthwash production chain based on environmental performance indicator. J. Clean. Prod. 2021, 311, 127679. [CrossRef]

36. Ultrafilm ${ }^{\circledR} 260$ LV. Informações Técnicas. Coalescentes. Oxiteno SA (In Portuguese). Available online: https://oxiteno.com/br/ pt-br/product/ultrafilm-260-lv / (accessed on 1 September 2021).

37. Li, Y.; Luo, C.-X.; Qian, C.; Chen, X. Trimerization of aldehydes with one $\alpha$-hydrogen catalyzed by sodium hydroxide. Chem. Pap. 2014, 68, 422-426. [CrossRef]

38. Aspen Plus ${ }^{\circledR}$ v 9.0. Aspen Technology Inc. Bedford, MA, USA. Aspentech. 2021. Available online: https://www.aspentech.com/ en/products/engineering/aspen-plus (accessed on 12 February 2021).

39. Peng, D.-Y.; Robinson, D.B. A New Two-Constant Equation of State. Ind. Eng. Chem. Fundam. 1976, 15, 59-64. [CrossRef] 
40. Klein, S.; Nellis, G. Thermodynamics, 1st ed.; Cambridge University Press: New York, NY, USA, 2011; pp. $651-776$.

41. Swan, P. An introduction to coalescing aids and Eastman film forming technologies. In Proceedings of the 36th International Conference on Coatings Technology, University of Pardubice, Pardubice, Czech Republic, 23-25 May 2005.

42. Gallagher, M.; Dalton, P.; Sitvarin, L.; Preti, G. Sensory and analytical evaluations of paints with and without texanol. Environ. Sci. Technol. 2008, 42, 243-248. [CrossRef]

43. Paes, M.X.; Medeiros, G.A.; Mancini, S.D.; Bortoleto, A.P.; Oliveira, J.A.P.; Kulay, L. Municipal solid waste management: Integrated analysis of environmental and economic indicators based on life cycle assessment. J. Clean. Prod. 2020, 254, 119848. [CrossRef]

44. SimaPro. SimaPRO 9.1.1. What's New? PRé Sustainability. Available online: https://simapro.com/wp-content/uploads/2020/1 0/SimaPro911WhatIsNew.pdf (accessed on 11 September 2021).

45. Greenhouse Gas Protocol. Available online: https://ghgprotocol.org/ (accessed on 11 September 2021).

46. International Organization for Standardization (ISO). Greenhouse Gases—Carbon Footprint of Products: Requirements and Guidelines for Quantification, 1st ed.; ISO 14067:2018; ISO: Geneva, Switzerland, 2006.

47. Publicly Available Specification (PAS). Specification for the Assessment of the Life Cycle Greenhouse Gas Emissions of Goods and Services PAS 2050:2008; British Standards Institution: London, UK, 2008; Available online: http://www.carbonconstruct.com/pdf/pas_20 50.pdf (accessed on 15 September 2021).

48. National Institute for Public Health and the Environment. LCIA: The ReCiPe Model. Available online: https://www.rivm.nl/en/ life-cycle-assessment-lca/recipe (accessed on 11 September 2021).

49. Bare, J.; Gloria, T.; Norris, G. Development of the method an U. S. normalization database for life cycle impact assessment and sustainability metrics. Environ. Sci. Technol. 2006, 40, 5108-5115. [CrossRef]

50. Bare, J.C.; Norris, G.; Pennington, D.W.; McKone, T.E. TRACI: The tool for the reduction and assessment of chemical and other environmental impacts. J. Ind. Ecol. 2002, 6, 49-79. [CrossRef]

51. Kumar, A.; Phillips, K.R.; Thiel, G.; Schröder, U.; Lienhard, J.H. Direct Electrosynthesis of Sodium Hydroxide and Hydrochloric Acid from Brine Streams. Nat. Catal. 2019, 2, 106-113. [CrossRef]

52. International Energy Agency (IEA). Energy Balances of OECD Countries 2015; OECD Publishing: Paris, France, 2015. [CrossRef]

53. Eastman Chemical Company. Standing the Test of Time-Eastman EATM Ester Alcohol: The Premier Coalescent. 2011. Available online: https: / / www.eastman.com/Literature_Center/M/M329.pdf (accessed on 11 September 2021).

54. Lee, B.; Naito, H.; Nagao, M.; Hibino, T. Alternating-current electrolysis for the production of phenol from benzene. Angez. Chem. Int. Ed. 2012, 51, 6961-6965. [CrossRef]

55. Tudor, R.; Ashley, M. Enhancement of industrial hydroformylation processes by the adoption of rhodium-based catalyst: Part I. Platin. Met. Rev. 2007, 51, 116-126. [CrossRef]

56. Tuţă, E.-F.; Bozga, G. Kinetics of propylene hydroformylation in the presence of modified rhodium triphenylphosphine catalyst. UPB Sci. Bull. Ser. B 2012, 74, 77-86.

57. Zimmermann, H.; Walz, R. Ullmann's Encyclopedia of Industrial Chemistry; Ethylene; Wiley-VCH: Weinheim, Germany, 2008. [CrossRef]

58. Uhlman, B.; Saling, P. The BASF eco-efficiency toolbox: Holistic evaluation of sustainable solutions. In Encyclopedia of Sustainable Technologies, 1st ed.; Abraham, M.A., Ed.; Elsevier Inc.: Amsterdam, The Netherlands, 2017; pp. 133-141.

59. Sakamoto, H.; Ronquim, F.M.; Seckler, M.M.; Kulay, L. Environmental performance of effluent conditioning systems for reuse in oil refining plants: A case study in Brazil. Energies 2019, 12, 326. [CrossRef]

60. Ronquim, F.M.; Sakamoto, H.; Mierzwa, J.C.; Kulay, L.; Seckler, M.M. Eco-efficiency analysis of desalination by precipitation integrated with reverse osmosis for zero liquid discharge in oil refineries. J. Clean. Prod. 2020, 250, 119547. [CrossRef]

61. Pithon, M.L.; Mierzwa, J.C.; Kulay, L. An environmental performance analysis of upgraded and integrated treatment techniques for drinking water production through reclamation. J. Sustain. Dev. Energy Water Environ. Syst. 2021, 10, 1090393. [CrossRef]

62. Florindo, T.J.; Florindo, G.I.B.M.; Talamini, E.; Costa, J.S.; de Léis, C.M.; Tang, W.Z.; Schultz, G.; Kulay, L.; Pinto, A.T.; Ruviaro, C.F. Application of the multiple criteria decision-making (MCDM) approach in the identification of carbon footprint reduction actions in the Brazilian beef production chain. J. Clean. Prod. 2018, 196, 1379-1389. [CrossRef]

63. Moore, C.C.S.; Kulay, L. Effect of the implementation of carbon capture systems on the environmental, energy and economic performance of the Brazilian electricity matrix. Energies 2019, 12, 331. [CrossRef] 